\title{
On the curious case of the recent decade, mid-spring precipitation deficit in central Europe
}

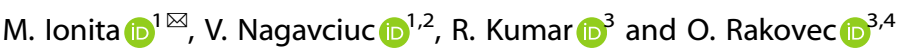

Central Europe has experienced a severe drought almost every April for the last 14 years consecutively, driven by record high temperatures, low flows, high evapotranspiration, and high soil moisture deficit. The dynamic of this recent and recurrent midspring dryness is not yet understood. Here we show that the period $2007-2020$ was characterized by a reduction of $\sim 50 \%$ of the usual April rainfall amount over large areas in central Europe. The precipitation deficit and the record high temperatures were triggered by a multiyear recurrent high-pressure system centered over the North Sea and northern Germany and a decline in the temperature gradient between the Arctic region and the mid-latitudes, which diverted the Atlantic storm tracks northward. From a long-term perspective, the precipitation, temperature, and soil moisture anomalies observed over the last 14 years have reached the highest amplitudes over the observational record. Our study provides an in-depth analysis of the hydroclimate extremes in central Europe over the last 140 years and their atmospheric drivers, enabling us to increase our dynamical understating of longterm dry periods, which is vital to enhance forecasting and mitigation of such events.

npj Climate and Atmospheric Science (2020)3:49; https://doi.org/10.1038/s41612-020-00153-8

\section{INTRODUCTION}

Hydroclimate variability affects natural and human systems globally, and extreme events such as floods, droughts, and heatwaves can alter ecosystem functioning, disrupt food production and security ${ }^{1,2}$, significantly impact ecology and carbon sequestration ${ }^{3,4}$, affect water availability ${ }^{5}$, damage human settlements and increase mortality ${ }^{6}$. These extreme events are likely to be exacerbated by global warming ${ }^{7,8}$. Droughts, which can extend over large areas and last for several years, are amongst the most damaging and expensive natural hazards. Since the beginning of the 21st century, Europe has experienced a series of prolonged summer heatwaves and droughts (e.g., 2003, 2010, 2013, 2015, $2018,2019)$, associated with substantial environmental damage and financial and human losses ${ }^{9-14}$. For example, the financial losses due to the 2018 drought were estimated to be 3.3 billion EUR, which made it the costliest single-year event in Europe ${ }^{15}$.

One of the key drivers of hydroclimate variability, both globally and regionally, is the prevailing large-scale atmospheric circulation. A wide range of approaches has been applied to characterize the large-scale atmospheric circulation and its links with European precipitation, ranging from global/hemispheric teleconnection patterns to weather regimes. One of the most important drivers of the European climate is the North Atlantic Oscillation (NAO) ${ }^{16}$. A positive phase of NAO is associated with a stronger jet stream and wetter conditions in central and northern parts of Europe, and drier than average conditions in the southern part of Europe ${ }^{17}$. NAO signature is particularly relevant in autumn, winter, and spring. During summer, the effects of NAO are restricted more to the northern and eastern parts of Europe ${ }^{18}$. Apart for NAO, other predefined teleconnection patterns have been linked with anomalous precipitation across Europe, such as the Scandinavian pattern (SCA), which is mainly related to high-latitude blocking over Scandinavia ${ }^{19}$, and the East Atlantic pattern ${ }^{20}$, or the East Atlantic/Western Russia pattern ${ }^{21}$. On a global scale, European precipitation has been linked with the El Niño-Southern Oscillation (ENSO), especially in spring ${ }^{22}$. However, the relationship between European precipitation and ENSO is non-stationary and varies with both season and region ${ }^{23,24}$. A similar non-stationary relationship between NAO and European precipitation was found by Vicente-Serrano and López-Moreno ${ }^{25}$. One possible reason for the non-stationary relationship between the European climate and predefined teleconnection indices might arise from the fact that these indices are defined based on sea level pressure or sea surface temperature data over a specific location ${ }^{14}$.

At shorter time scales, several studies have linked the precipitation variability with particular weather regimes/types. These weather regimes are often used to characterize the regional response of precipitation anomalies because they are defined and calibrated over relatively small domains ${ }^{26}$. Fleig et al. ${ }^{27}$ have shown that weather types representing a high-pressure center over the region affected by meteorological drought promote the development of hydrologic droughts. These weather types are associated with the advection of warm and dry air over specific regions, hence they promote drought development. Over the Iberian Peninsula, seven weather types (WTs) have been identified to capture a high percentage $(\sim 70 \%)$ of the monthly Iberian precipitation variability ${ }^{28}$.

Another important driver of European precipitation, at synoptic time scales, is atmospheric blocking ${ }^{29}$. Atmospheric blocking is a large-scale mid-latitude atmospheric phenomenon mostly associated with persistent quasi-stationary, synoptic-scale high-pressure systems. It exerts a strong impact on resulting weather patterns and is therefore often associated with extreme weather, such as heat waves ${ }^{30,31}$, cold spells ${ }^{32}$, and floods ${ }^{21,33}$. The relationship between precipitation and atmospheric blocking has been widely investigated and North Atlantic and European blocking have been found to have a significant influence on winter precipitation over large areas of Europe ${ }^{29}$. Dry (wet) winters

\footnotetext{
${ }^{1}$ Alfred Wegener Institute for Polar and Marine Research, Bremerhaven 27570, Germany. ${ }^{2}$ Forest Biometrics Laboratory, Faculty of Forestry, Stefan cel Mare University, Suceava 720229, Romania. ${ }^{3}$ UFZ-Helmholtz Centre for Environmental Research, Leipzig 04318, Germany. ${ }^{4}$ Faculty of Environmental Sciences, Czech University of Life Sciences Prague, Praha, Czech Republic. ${ }^{凶}$ email: Monica.lonita@awi.de
} 
near the British Isles and wet (dry) winters west of the Iberian Peninsula are associated with blocking (non-blocking) episodes over the Euro-Atlantic region. Rimbu et al. ${ }^{32}$ explored the relationship between summer precipitation extremes and atmospheric blocking in the eastern part of Europe and they showed that blocking events in the sectors $\left(0^{\circ}-40^{\circ} \mathrm{E}\right.$ and $\left.50-70^{\circ} \mathrm{E}\right)$ were associated with enhanced precipitation variability during summer. Over the European domain, Sousa et al. ${ }^{34}$ have shown that the regions situated directly under the influence of blocking are characterized by a decreased frequency of rainfall and a high frequency of extreme rainfall on the southern flank of the blocking events. In terms of extreme precipitation, more recently Lenggenhager and Martius ${ }^{35}$ found a significant relationship between the odds of heavy precipitation over Europe and blocking episodes over the North-Atlantic region.

To date, research has focused strongly on winter and summer and particularly on heavy precipitation events. The winter months are the most active from a dynamic point of view and the perturbations of the large-scale atmospheric circulation can reach very high amplitudes ${ }^{36}$, while the summer season has featured a relatively large number of extreme events (e.g., floods, droughts, heatwaves) especially since the beginning of the 21 st century ${ }^{37}$. The importance of spring hydroclimatic background conditions for the upcoming summer season has been emphasized in a number of studies, but their triggering drivers and their variability still lack a dynamical understanding. In a recent study, Hänsel et al. ${ }^{38}$ have shown that over the last years there is a significant negative trend in the precipitation amount, in spring, over the central part of Europe. It has been shown that antecedent moisture deficits are related to the number of hot days and maximum heat waves duration, in summer, both at European ${ }^{39}$ and global scales ${ }^{40}$. Quesada et al. $(2012)^{41}$ have shown that spring soil moisture deficits, in combination with different weather types, are important factors in controlling the occurrence of hot days in summer, over Europe. Hanel et al. $^{13}$ argued that the recent droughts over Europe were often initiated during the vegetation period, while the previous droughts over the last 250 years were mostly initiated during late summer/early autumn. Overall, much less attention has been given to the variability of the European climate and its driving factors, in the transition seasons (e.g., spring and autumn), even though climate-related anomalies and resulting land surface conditions (e.g., soil moisture and/or soil moisture memory, snow cover) during the transition seasons are as important as those in winter and summer.

Motivated by the knowledge-gap regarding the pattern and drivers of long-term precipitation variability during the transition months, we investigate the last decade of spring drying over central Europe in the context of the large-scale atmospheric circulation associated with central European precipitation variability during the last 140 years. Our study uses a range of model and observation-based hydrometeorological datasets (see "Methods" section) to perform an in-depth analysis of recent and historical periods of precipitation deficit and their triggering mechanisms, elucidating this complex phenomenon, which is vital to enhance forecasting and mitigation.

\section{RESULTS}

Central European hydroclimate over the last decade

To characterize the changes in European climate over the last decade, we computed the anomalies over the period 2007-2020 for precipitation (PP), mean air temperature (TT), the Standardized Precipitation Index for one month accumulation period (SPI1), and the Standardized Potential Evapotranspiration Index for one month accumulation period (SPEI1), relative to the climatological period 1961-1990 (Fig. 1 and Supplementary Fig. 1; see also Methods for details). The period $2007-2020$ is characterized by a significant (99\% confidence level based on a two-tailed t-test) reduction in April precipitation amount (Fig. 1a) and drier April months (Supplementary Fig. 1) over large parts of Europe. A strong increase in the evapotranspiration rates is observed over the whole European region, throughout the last decade (Supplementary Fig. 1c), while statistically significant changes are concentrated over central and western Europe. The soil moisture anomalies (Supplementary Fig. 1d) follow the overall pattern of PP (Fig. 1), SPEI1 (Supplementary Fig. 1a) and SPI1 (Supplementary Fig. 1b), with significant changes over most of central Europe. The only difference is observed over the Iberian Peninsula, where the soil moisture anomalies indicate a strong drying trend over the last 14 years, while no significant precipitation deficit is observed. Figure 1 and Supplementary Fig. 1 suggest that the most affected countries, in terms of precipitation deficit over the last 14 years, are Germany, Poland, the western part of the Czech Republic, Hungary, and Ukraine. April temperatures during the period 2007-2020 were up to $3^{\circ} \mathrm{C}$ higher than normal in the southern and central parts of Europe (Fig. 1b).

Since the highest amplitudes of the precipitation deficit are observed over Germany (Fig. 1a) and because long-term observations and reconstructions (1881-2020) are available at the country level (see Methods), we focus further on this region. Supplementary Fig. 2a shows that April precipitation was reduced on average by $\sim 30 \mathrm{~mm}$ over Germany during the period 2007-2020; a statistically significant reduction representing about $50-60 \%$ of April rainfall in some regions (Supplementary Fig. 2b). In terms of mean air temperature, during the period 2007-2020 the highest amplitudes were recorded over the instrumental period. The driest period both at local scale (Fig. 1c), and regionally (e.g., over different parts of the country Supplementary Fig. 3), was recorded between 2007 and 2020, while the wettest period was recorded between 1911 and 1940 (Fig. 1c). Overall, the period 2007-2020 was $\sim 2.8^{\circ} \mathrm{C}$ warmer compared to the period 1881-1910 (Fig. 1d; changes are statistically significant based on the two-sample Kolmogorov-Smirnov test). The highest temperature anomalies over Germany were recorded during this period, with April 2018 being the warmest on record (Fig. 2a). The period 2007-2020 is also one of the driest on record, with 12 consecutive Aprils having negative precipitation anomalies (Fig. 2b). The extreme water deficit observed over the last decade can be also seen in higher evapotranspiration (ETO) rates (Fig. 2c) and soil moisture deficits (Fig. 2d). Both ETO and SM feature extreme positive (ETO) and negative (SM) anomalies for 10 consecutive years, 2007 being the driest on record when looking at the SM anomalies. The top three driest Aprils on record (2007-rank 1, 2014-rank 2, and 2019rank 3), based on the SM data, were recorded over the period 2007-2019. A similar pattern of more than 12 consecutive years with negative precipitation anomalies was recorded during the 1881-1895 period (Fig. 2b). Nevertheless, this period was characterized by alternating years with positive and negative temperature anomalies (Fig. 2a), with much lower amplitude than those of the last decade, and thus keeping the soils in normal conditions, without any exceptional anomalies (Fig. 2d). The rainfall deficit and the high temperatures over the last decade have also led to extremely low river flows. Some of the most important waterways in Europe have been seriously affected, with enormous economic consequences ${ }^{14}$. April 2020, the driest of the last 140 years, has set a new record for low flows in the Elbe River (north-eastern part of Germany) (Fig. 2e). The rainfall deficit and the extremely high April temperatures were accompanied by anomalously sunny conditions (Supplementary Fig. 4). April 2020 was the sunniest on record (70 years), with an average sunshine duration, at country level, of $\sim 292 \mathrm{~h}$. 

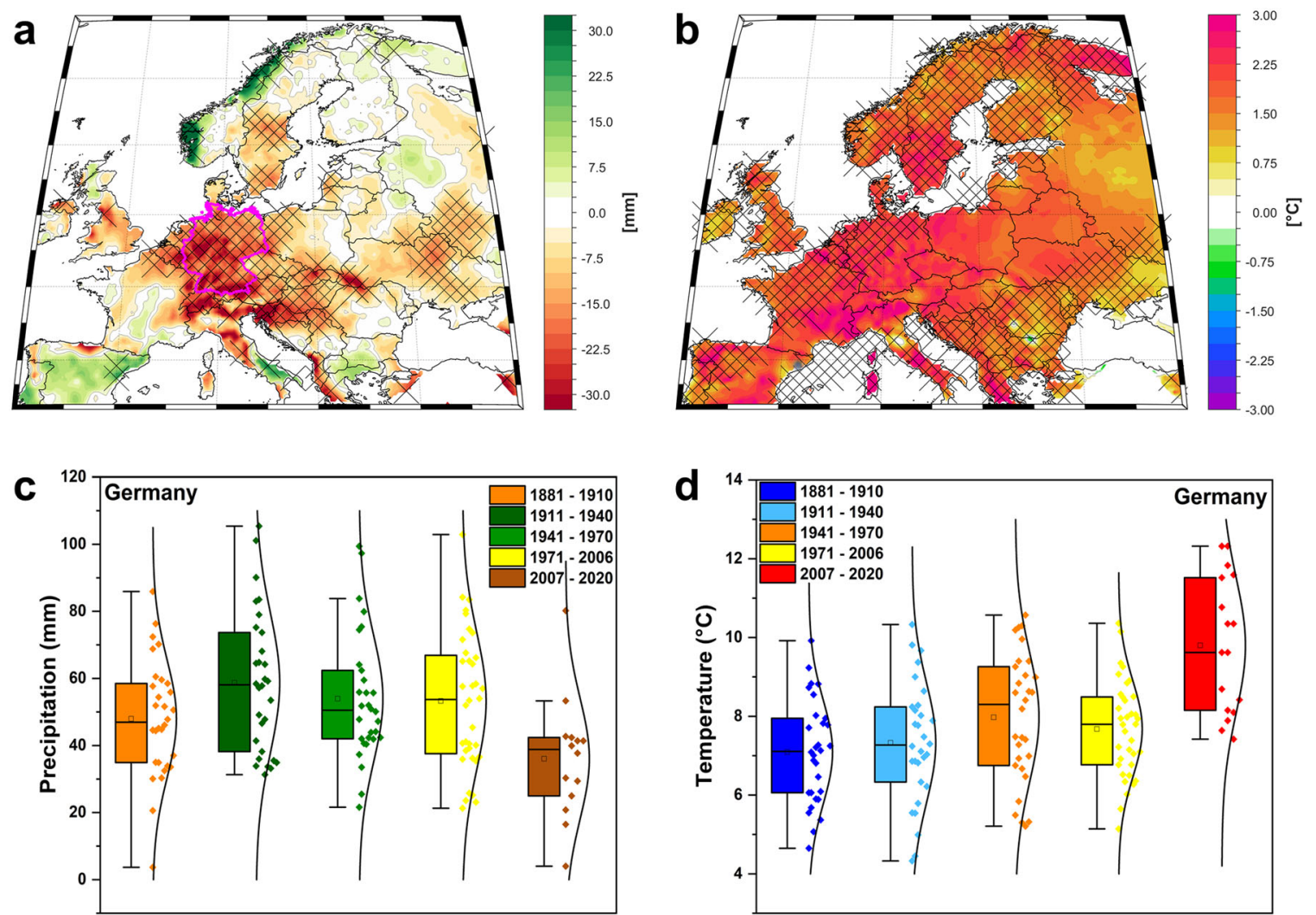

Fig. 1 Variability of precipitation and temperature at country level. a April precipitation anomalies for the period 2007-2020. $\mathbf{b}$ April mean temperature anomalies for the period 2007-2020; The anomalies are computed relative to the climatological period 1961-1990. The hatched areas in (a) and (b) indicate anomalies significant at $95 \%(p<0.05$ based on a two-tail t-test). $\mathbf{c}$ Box plots of April precipitation for different time spans averaged over Germany (magenta contour in a). d Box plots of April mean air temperature for different time spans averaged over Germany.

Large-scale drivers over the last decade

Persistent high-pressure systems play a significant role in the generation of heatwaves, soil moisture deficit and droughts at both global and regional scales ${ }^{42-45}$. To test if the prevailing largescale circulation played a role in the extreme precipitation deficit and high temperatures over the period 2007-2020, we computed the large-scale atmospheric circulation anomalies during April over the last 14 years (Fig. 3a), with respect to the climatological period 1961-1990 (see Methods). The Z500 anomalies were characterized by a high-pressure system centered over the North Sea and Germany flanked by a low-pressure system over the central North Atlantic basin and a low-pressure system over Russia. The North Sea high-pressure system blocks the prevailing mid-latitude westerlies and shifts the Atlantic storm tracks northward (Supplementary Fig. 5), leading to extremely high temperature and precipitation deficit over the central part of Europe. The presence of the high-pressure system centered over the North Sea results in a bifurcation of the storm tracks north and south (Supplementary Fig. 5). In some years, this high-pressure system over the North Sea persisted throughout the summer months, shifted its center either northwards or southward, and amplified the drought and led to long-lasting heat waves, like in the case of 2015 and $2018^{9,11}$. In a long-term perspective, robust positive trends in the April Z500 were detected over the period 1948-2020 (Supplementary Fig. 6). A positive and significant trend was observed over the North Sea and the northern part of Germany, while a negative, but not significant Z500 trend, was observed west off the Iberian Peninsula. Additionally, a significant and positive trend was also observed in front of the eastern coast of the U.S. A similar increase in the spring (March-April-May) Z500, centered over the North Sea was found by Horton et al. ${ }^{46}$, who have shown that there were robust positive trends in the occurrence of anticyclonic patterns and hot extremes, in spring, over the North Sea and Europe during satellite-era (1979-2014 in their study).

As well as the large-scale atmospheric circulation, the climate of the mid-latitudes is influenced by transient synoptic disturbances co-existing with less common, but persistent circulation patterns. A significant modification in the amplitude, frequency, and/or location of these synoptic disturbances can lead to substantial changes in regional climates ${ }^{47}$. One of the most important synoptic-scale disturbances influencing extremes over Europe is atmospheric blocking. Since the spatial structure of the Z500 anomalies, observed over the period 2007-2020, resembles an omega-like atmospheric blocking pattern ${ }^{47}$, we computed the location and the frequency of a $2 \mathrm{D}$ blocking index ${ }^{48}$ over the period 1948-2020 and evaluated the blocking events relative to the climatological period 1961-1990 (Fig. 3b; see Methods). There is a significant increase in the occurrence of atmospheric blocking over most of the central parts of Europe during the recent period 2007-2020. A corresponding yearly evolution of the 2D blocking index, during 2007-2020 is shown in Supplementary Fig. 7. The years with the highest anomalies in the frequency of blocking over the central part of Europe (e.g., 2007, 2015, 2018, 2019, and 2020) are also the years when extreme rainfall deficit is observed over Germany (Supplementary Fig. 8). In agreement with our findings, Sousa et al. ${ }^{34}$ have shown that the location of the largest precipitation anomalies, over the northern part of Europe, usually follows the position of the blocking centers.

To have a better overview of the large-scale drivers causing precipitation deficits during 2007-2020, we further analyzed the frequency of weather types for April. The advantage of looking at 


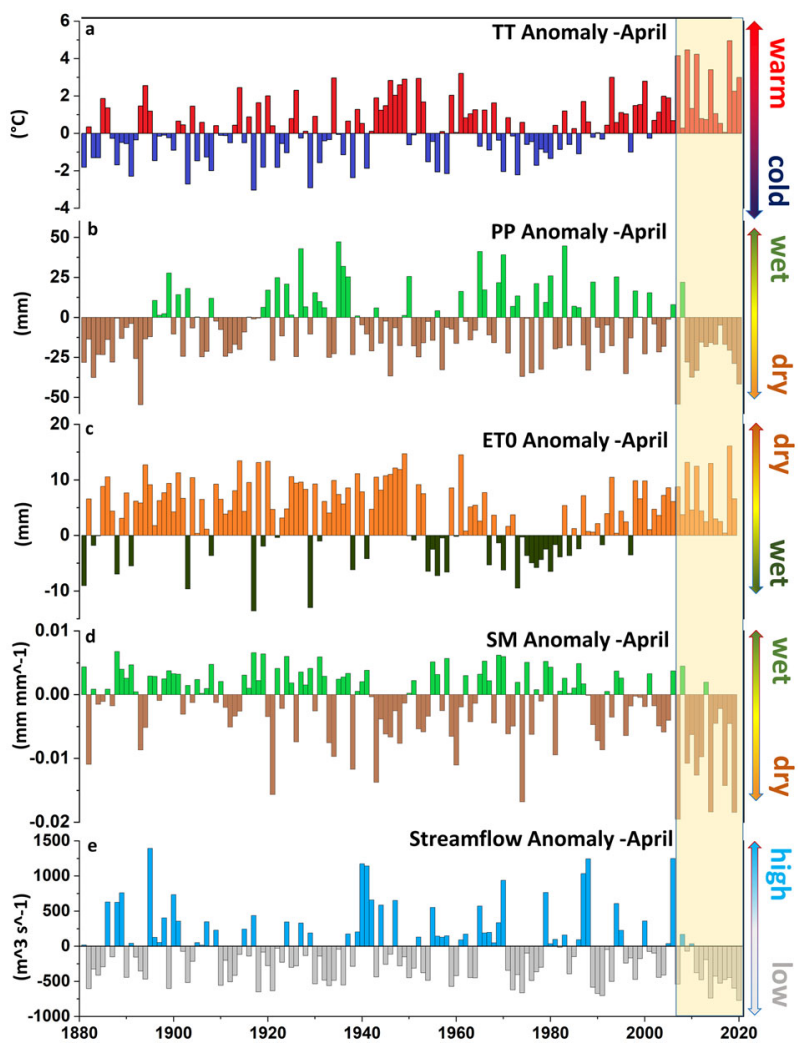

Fig. 2 Hydroclimatic anomalies at country level. April anomalies averaged over Germany for. (a) the mean air temperature. b Precipitation. c Actual evapotranspiration (ETO). d Soil moisture. e Streamflow for the Elbe River at Neu Darchau gauging station. The anomalies are computed relative to the climatological period 1961-1990.
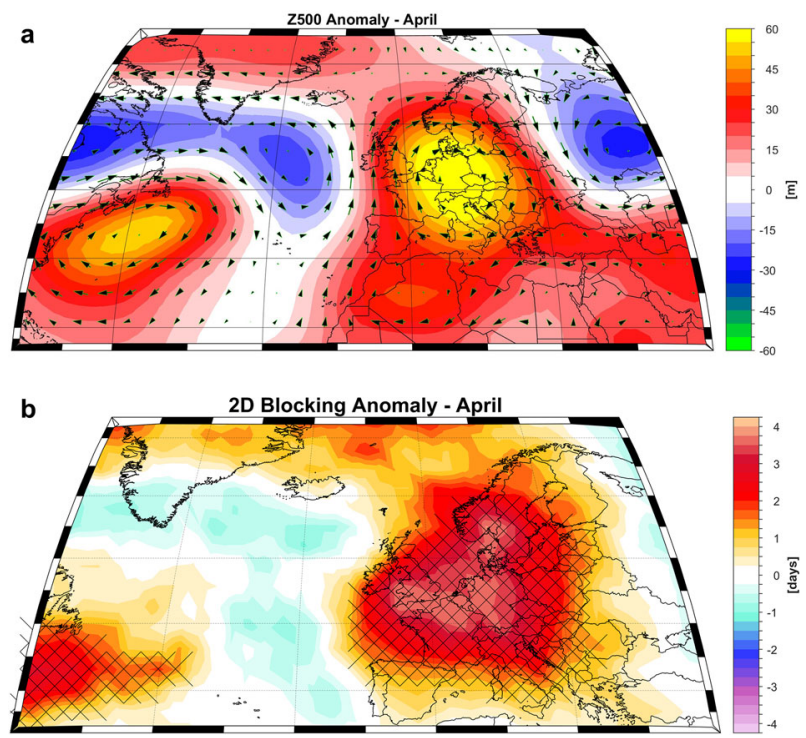

Fig. 3 Large-scale atmospheric circulation anomalies. a April geopotential height anomalies at $500 \mathrm{mb}$ (Z500) over the period 2007-2020 relative to the climatological period 1961-1990. b Same as (a) but for the two-dimensional (2D) blocking index. The hatched areas in (b) indicate anomalies significant at $95 \%$ significance level based on a two-tailed $t$-test. synoptic scales is that the large-scale atmospheric circulation can be split into multiple regime types rather than a few predefined indices (e.g., NAO, ENSO). While predefined teleconnection indices focus on two stages of the same pattern (i.e., positive and negative), weather types may explain a higher proportion of the precipitation variability. We used the objective weather situation classification (WLK) of German Meteorological Service (DWD) ${ }^{49}$ and computed the cyclonic and anticyclonic weather types for April, 1980-2020 (Supplementary Fig. 9). We observed a significant change, estimated over the 1980-2020 period, in the frequency of anticyclonic types vs cyclonic types. Over the period 2007-2020, the April frequency of anticyclonic weather types is higher compared to the cyclonic weather types. The years with the highest amplitude of anticyclonic weather types are 2007 (27 days out of 30) and 2020 ( 26 days out of 30). These are also the years with the smallest precipitation amount and lowest soil moisture (Fig. 2).

By analyzing the large-scale drivers over the period 2007-2020, the most striking results are those indicating a positive and significant increase in the occurrence of anticyclonic circulation over the North Sea and central Europe. The high-pressure center over the North Sea deflects the storm tracks northward, leading to extremely dry and warm conditions in April. The large-scale analysis was performed at both monthly and synoptic time scales and the results converge in the same direction: April is becoming unusually warm, dry, and sunny and these changes are mainly driven by changes in the large-scale atmospheric circulation. We performed the same analysis also for March and May (not shown), but no significant changes have been found in either the precipitation anomalies or in the large-scale atmospheric circulation.

\section{Large-scale drivers in a long-term context}

It is clear that the April months during the last decade (2007-2020) were exceptional across central Europe. The main natural drivers of precipitation deficit, droughts, and heatwaves are persistent high-pressure systems, as well as global or basinwide sea-surface temperature anomalies ${ }^{11,43,44,50,51}$. Long-lasting blocking situations associated with stationary Rossby waves are the main drivers of summer droughts and heatwaves ${ }^{44,52}$. To analyze the drivers of the exceptional precipitation deficit over the central part of Europe from a long-term perspective, we applied a Canonical Correlation Analysis (CCA) between April precipitation and April North Atlantic Z500 for the short NCEP period (1948-2020, NCEP-V1), and the longer precipitation dataset starting in 1881 (ww.dwd.de) and the $20^{\text {th }}$ century reanalysis dataset V3 (NCEP-V3) ${ }^{53}$. CCA identifies coupled modes of variability and their associated temporal components in the PP/ Z500 data sets (see "Methods" section).

Figure 4 shows the first CCA mode for April Z500 (Fig. 4a) and April PP (Fig. 4b). The first CCA pattern (CCA1) explains $46.5 \%$ of the total variance for PP and $11.24 \%$ of the total variance for $Z 500$. The first CCA associates simultaneously negative (positive) PP anomalies (Fig. 4b) over the central part of Europe with an extended high (low) pressure system centered over the North Sea and northern Germany and a low (high) pressure system over the Azores (Fig. 4a). The year to year variations of the normalized temporal components of the first CCA pairs are shown in Fig. 4c. The two time-series are significantly correlated $(r=0.88,99 \%$ significance level). Both canonical time series present strong interannual variability during 1948-2006, while during 2007-2020 the amplitudes of the Z500/PP anomalies indicate mostly an increase in the geopotential height and a rainfall deficit.

The dry (wet) periods identified by the CCA are similar to the dry (wet) periods observed in the April PP anomalies across 
a

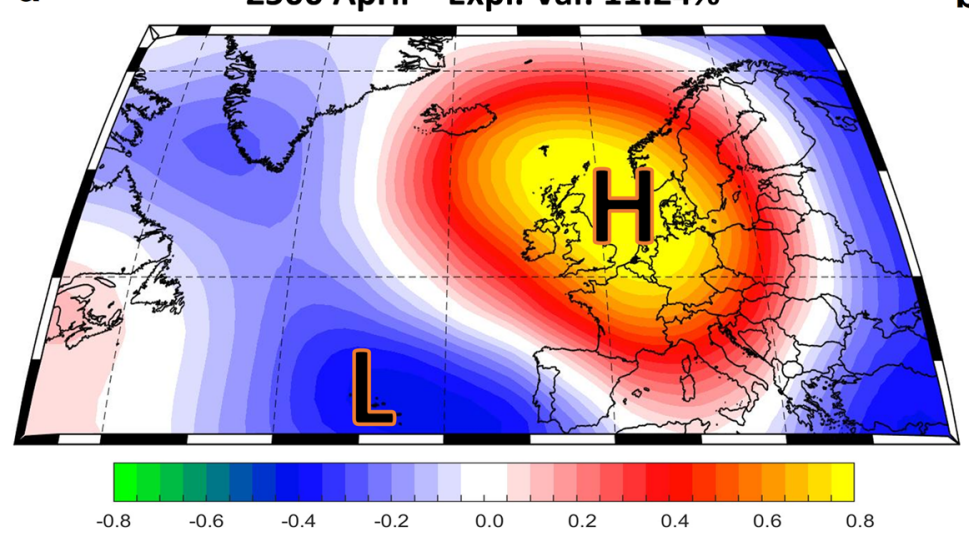

b

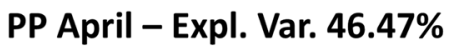

C
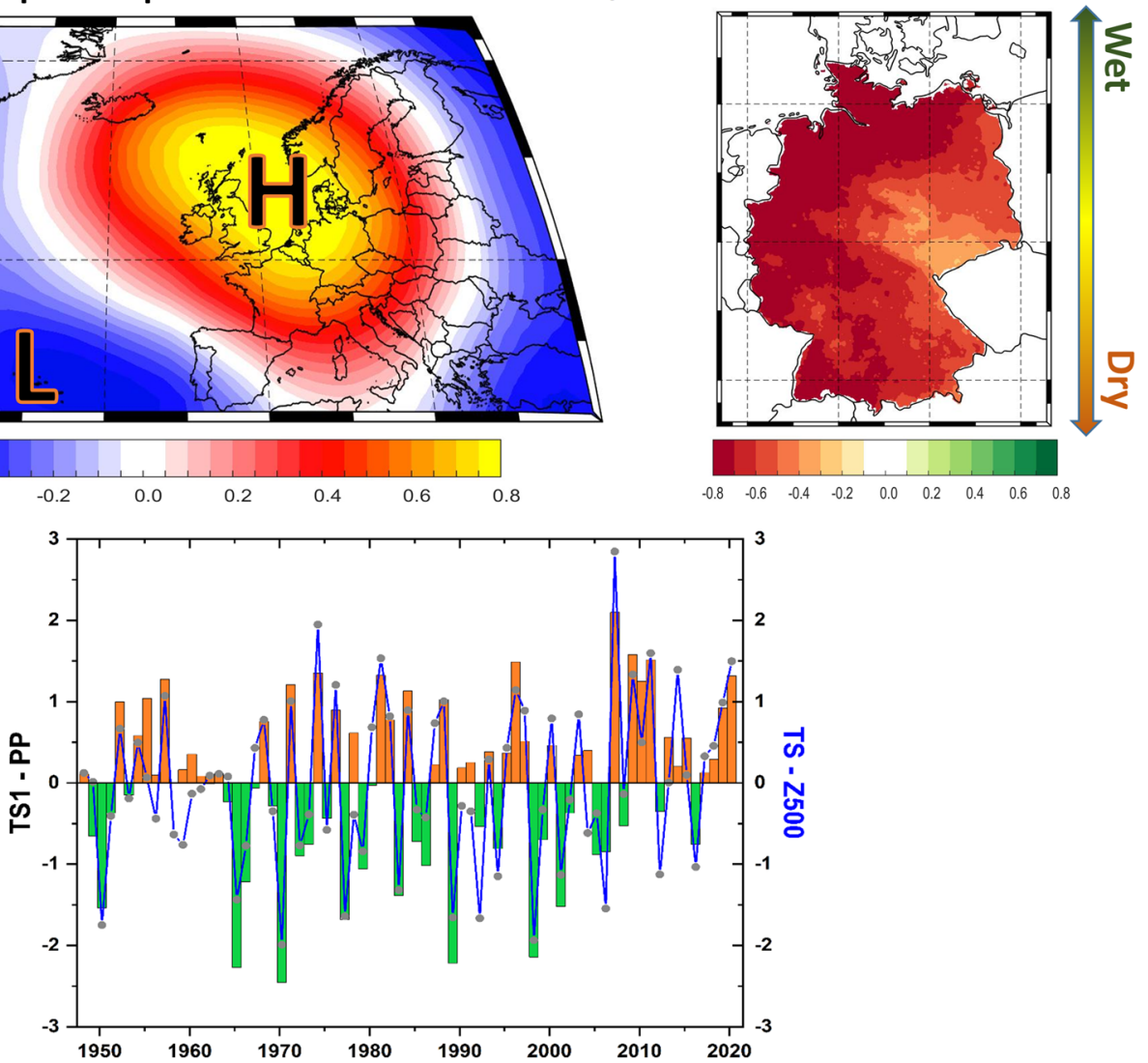

Fig. 4 Coupled modes of variability (CCA). The first coupled mode of variability between (a) April geopotential height at $500 \mathrm{mb}$ (Z500) and (b) April precipitation (PP) averaged over the period 1948-2020. c The standardized amplitudes corresponding to CCA1-Z500 (blue line) and CCA1-PP (colored bars).

Germany (Fig. 2b). The same spatio-temporal variability is obtained when we applied the CCA over the longer period 1881-2015 (Supplementary Fig. 10): dry (wet) periods over the central part of Europe correspond with high (low) pressure systems centered over the North Sea and the northern part of Germany. The high-pressure system leads to the advection of warm and dry air from the eastern part of Europe and increased incoming solar radiation, which in turn hinders precipitation and reduces the soil moisture content. For the period 1881-1895 the amplitude of the normalized temporal components of April PP and Z500 is similar to the one observed over the period 2007-2020 (Fig. 4 and Supplementary Fig. 10). The main difference between these two periods is the temperature, SM, ETO, and streamflow (Fig. 2). The fact that the hydrological components show a very distinct evolution for these two periods emphasizes the increasing role of temperature during the last decades. Finally, the spatial structure of the Z500 anomalies observed over the last decade (Fig. 3a) resembles the spatial structure obtained by the CCA analysis for the Z500 field (Fig. 4a), which supports our findings that anomalously dry (wet) Aprils are mainly caused by high (low) pressure systems over the analyzed region.

\section{Stability maps}

The global atmospheric circulation shows several distinct variability patterns, all of which are reflected in the surface climate (e.g., NAO, ENSO, SCA, EAWR). Nevertheless, the relationship between the European climate and global and/or hemispheric teleconnection patterns was found to be limited due to non-stationarity issues $^{23,54}$. The non-stationary issue may arise in any type of analysis between different types of variables. In the previous section, we used CCA to identify the large-scale drivers of April PP, but CCA does not consider if the relationship between two variables is stationary in time or not. To overcome the problem of non-stationarity and to test if the identified coupled mode of variability between April PP and April Z500 is stable over time, we employed a methodology used for the monthly to seasonal prediction of the mean runoff of the Elbe River ${ }^{55,56}$ and in dendroclimatological studies ${ }^{57,58}$. A detailed description of the methodology is given in lonita $(2017)^{59}$.

In this respect, we correlated the April precipitation averaged over Germany with the April Z500 field, in a moving window of 41 years. The results of this analysis are depicted in Fig. $5 \mathrm{a}$ as a stability map highlighting grid-points where April PP and Z500 are significantly correlated at $95,90,85$, and $80 \%$ significance level for more than $80 \%$ of the 41 -year time windows. The $80 \%$ and $85 \%$ levels are used as "buffer zones" and only grid cells where the correlation is above $95 \%$ significance level, are retained for further analysis. April PP is stable and negatively correlated with April Z500 over a large region centered over the North Sea and the northern part of Germany. April PP is also stable and positively correlated with $Z 500$ in a region situated west off the Iberian Peninsula. By employing the same type of analysis, we found a stable and significant relationship between April PP and the 2D atmospheric blocking index (Supplementary Fig. S11). Thus, the relationship between April PP and April large-scale atmospheric circulation is stable in time, and dry (wet) years are associated with a high (low) pressure system centered over the North Sea and the northern part of Germany. Based on the stability map identified in Fig. $5 \mathrm{a}$, we defined a Z500 index averaged over the North Sea 
6
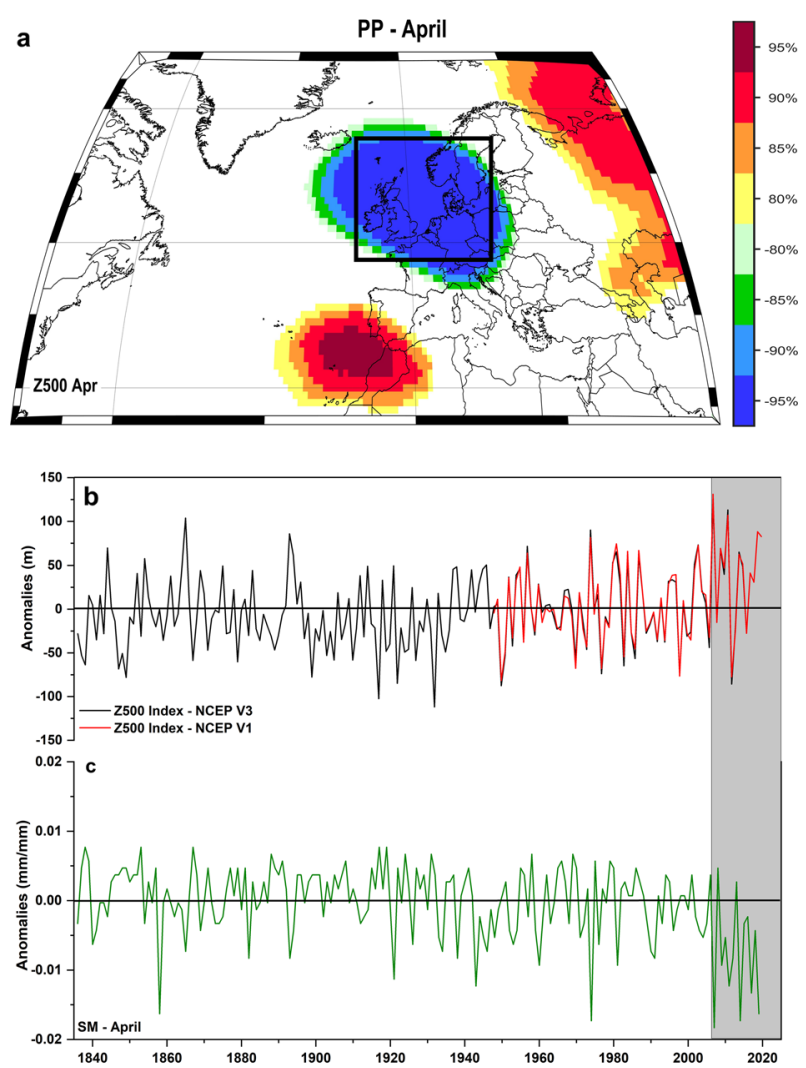

Fig. 5 Stability maps. a Stability map of the correlation between April PP averaged over Germany and April Z500 over the period 1881-2015. Regions where the correlation is stable, positive, and significant, for at least $80 \%$ of the 41 -year windows are shaded as colored scale indicates. b The time series of April Z500 averaged over the black box in Fig. 5a. c The time series of April soil moisture averaged over Germany for the period 1836-2015. In b the black line indicates the April Z500 index based on the NCEP-V3 dataset (1835-2015) while the red line indicates the April Z500 index based on the NCEP-V1 dataset (1948-2020). The correlation coefficient between the two-time series $\mathbf{b}$ and $\mathbf{c}$ is $r=-0.53$ (99\% significance level).

(black square in Fig. 5a) to place the evolution of the increased high pressure over this region in a long-term context (i.e., over the period 1836-2020 as depicted in Fig. 5b). The April Z500 index exhibits strong interannual variability over the last 175 years, with the highest amplitudes since the beginning of the $21^{\text {st }}$ century. Notably, three of the top seven values of this index were recorded from 2007 onwards. The 7 highest values of the index were, in rank order, 2007, 2011, 1865, 1974, 2019, 1893 and 2020. All these years were also marked as having extreme precipitation deficit (Fig. 2b) and reduced soil moisture (Figs 2c and 5c). Overall, the amplitude anomalies for both Z500 and resulting PP and SM recorded in the $21^{\text {st }}$ century are the highest ones over the last 175 years (Fig. 5b, c).

Arctic amplification and mid-latitudes atmospheric circulation Recent studies have shown that anthropogenic global warming, particularly the Arctic amplification, has contributed to the increasing number of summer heat wave events in Europe ${ }^{60,61}$. The major dynamical features is the position and structure of the jet stream and planetary wave activity ${ }^{62-64}$. Jet streams are primarily driven by the difference in temperature between the polar and mid-latitudinal regions and the weakening of the zonal mean jets is generally due to the reduction of the equator-to-pole thermal gradient associated with changing surface conditions.
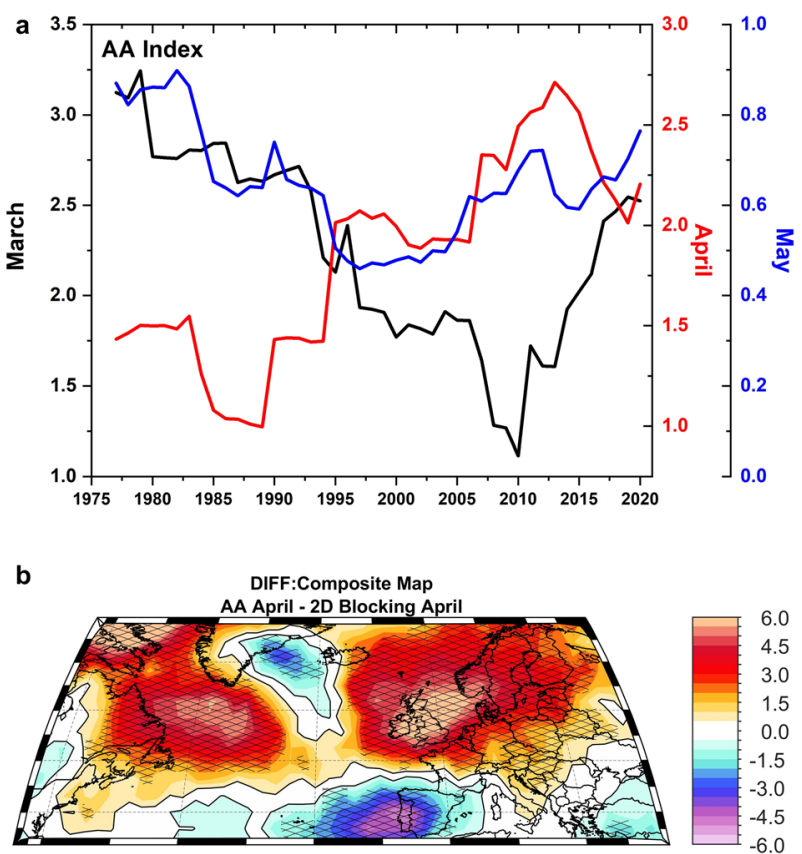

Fig. 6 Arctic amplification and 2D atmospheric blocking. a Arctic amplification monthly time series based on the differences in the $2 \mathrm{~m}$ air temperature anomalies between the Arctic region $\left(70^{\circ} \mathrm{N}-90^{\circ}\right.$ $\mathrm{N})$ and mid-latitudes $\left(30^{\circ} \mathrm{N}-60^{\circ} \mathrm{N}\right)$. b The composite map (DIFF = High-Low) between the standardized times series of April AA index and the 2D atmospheric blocking frequency (see data and "Methods" section). The hatched areas indicate anomalies significant at $95 \%$ significance level based on a two-tailed t-test. Units: a $\left({ }^{\circ} \mathrm{C}\right)$ and (b) number of days. Data source: the AA index is computed based on the GISS Surface Temperature Analysis (GISTEMP) ${ }^{87}$, version 4. Dataset accessed 2020-09-05 at data.giss.nasa.gov/gistemp/.

European heat waves have often been associated with anomalous circulation patterns characterized by the weakening of the zonal mean jets, the quasi-resonant amplification of planetary waves, and persistent blocking conditions over midlatitude Eurasia that produce prolonged hot surface conditions ${ }^{65}$.

The period 2007-2020 was characterized by a very weak temperature gradient between the Arctic region and mid-latitudes (Fig. 6a). Here, the Arctic Amplification (AA) is measured as the change in surface air temperature over the Arctic $\left(70^{\circ} \mathrm{N}-90^{\circ} \mathrm{N}\right)$ relative to mid-latitudes $\left(30-60^{\circ} \mathrm{N}\right)$. AA shows a sharp increase (weaker gradient) especially in April when compared to March and May (Fig. 6a). To test if AA in April has any influence on the largescale atmospheric circulation at mid-latitudes, we computed the composite maps (see Methods) between April AA index and the April 2D atmospheric blocking (Fig. 6b). From Fig. 6b we can infer that years characterized by a weaker temperature gradient between the Arctic region and mid-latitudes are associated with enhanced atmospheric blocking over the British Isles and the North Sea. The location of the increased blocking frequency in response to a weak gradient between the Arctic region (Fig. 6b) and the mid latitudes is identical with the location of the anomalies of the 2D atmospheric blocking over the period 2007-2020 (Fig. 3b). This co-dependence of the large-scale atmospheric circulation and $A A$ is also tested using the climate model simulations of Coupled Model Intercomparison Project (CMIP5) for two Representative Concentration Pathways (RCPs): ${ }^{66}$ RCP2.6 and RCP8.5, respectively. In both cases the relationship between April AA and April Z500 averaged over the North Sea and the central part of Europe (black box in Fig. 5a) seems to be a consistent feature: a weak $A A$ is complemented by an increase in 
the geopotential height over the analyzed region (Supplementary Fig. 12). Under RCP8.5 there is an amplification of the $500 \mathrm{hPa}$ height anomalies of $\sim 80 \mathrm{~m}$ until 2100 over the analyzed region while for the RCP2.6 scenario, the $500 \mathrm{hPa}$ shows a peak between 2000-2020, followed by a decrease in the amplitude afterwards.

Observations and climate model simulations clearly suggest that AA could partly explain the observed changes in the large-scale atmospheric circulation over the study region in the last two decades. AA can also potentially modulate the future occurrence of persistent high-pressure systems over the North Atlantic region. The co-variability between a weak poles-to-mid-latitude gradient and reduced precipitation over the mid-latitudes has been shown to be a persistent feature also during the Holocene ${ }^{67}$. By analyzing the influence of the Arctic warming on the mid-latitude precipitation during the Holocene, Routson et al. (2019) ${ }^{67}$ have shown that when the Arctic is warmer, the jet stream and other wind patterns tend to be weaker, leading to less precipitation over the midlatitudes. Nevertheless, the Z500 trends detected here cannot be fully attributed to anthropogenic or natural causes. Attribution and projection require an increased understanding of underlying causes of the large-scale atmospheric circulation trends, as well the ability to identify the signal of an anthropogenically forced trend from the noise of internal decadal-scale climate variability ${ }^{68}$.

\section{DISCUSSION}

In this study we assess the severity and persistence on the mid-spring drying in central Europe over the last 14 years and its large-scale atmospheric drivers. Compared to previous long-lasting mid-spring dryness (e.g., 1881-1895), the multiyear average of precipitation, mean air temperature, soil moisture and evapotranspiration, during the last 14 years are characterized by extreme values, with record breaking anomalies for $\Pi$ and SM. The current long-lasting drought, in April, over central Europe is due to a combination of extremely low precipitation, extremely high temperature, depleted soil moisture and a significant increase in evapotranspiration, which in turn have led to record low flows over the central European Rivers ${ }^{69}$. This long-lasting drought, in mid-spring, is associated with an increase in the frequency of anticyclonic weather types and with a multiyear persistence of a high-pressure system centered over the North Sea and Germany, flanked by a low-pressure system over the central North Atlantic basin and a low-pressure system over western Siberia. The configuration of the Z500 anomalies over the last 14 years led to a shift of the Atlantic storm tracks northwards. The persistence and recurrence of the highpressure system centered over the North Sea and northern Germany, can be seen as a European analog of the famous Ridiculously Resilient Ridge (RRR) which was the main driver of the 2013-2016 Californian drought $^{70}$. The predominance of anticyclonic atmospheric circulation regimes seems to be a prerequisite for the development of a very dry and warm mid-spring. In a long-term perspective, our results indicate that the contribution from rising temperatures is becoming more important for the occurrence of low flow periods and droughts over central Europe, compared to previous long-lasting droughts (e.g., 1881-1895). This trend is broadly consistent with model projections of increasing soil moisture droughts due to anthropogenic warming ${ }^{71}$.

Part of the significant increase in geopotential height, over the North Sea and central Europe can be explained by a weakening of the temperature gradient between the Arctic region and the midlatitudes, which influences the position and structure of the jet stream and planetary wave activity. In this study we show that the reduced temperature gradient is associated with more persistent weather patterns (e.g., atmospheric blocking), which in turn leads to long-term precipitation deficit.

Based on our analysis we conclude: (i) in a long-term context, for central Europe, the period 2007-2020 ranks as the driest and warmest since 1881; (ii) this drying was forced by the prevailing large-scale atmospheric circulation, featuring an increase in the frequency of atmospheric blocking over the North sea and central
Europe; (iii) the increased frequency of atmospheric blocking can be, at least partially, explained by the weakening of the temperature gradient between the Arctic region and the midlatitudes, which in turn influences the strength of the jet stream and the persistence of extreme weather events.

Overall, the month of April seems to be a very curios case from a climatological point of view, especially since the beginning of the 21st century. A similar analysis, over the same region, was performed for March and May, but no significant changes in the precipitation and temperature variability over the last decade have been noticed (not shown). This study highlights the importance of analyzing the hydroclimate over transitions months/seasons. Hanel et al. ${ }^{13}$ have shown that the recent summer European droughts (e.g., 2003, 2015) were initiated in spring primarily as a result of compounding effects of low precipitation and high temperatures leading to extreme soil water deficits. Moreover, the climate projections indicate an increased risk of drought occurrence during critical periods for agricultural crops in central Europe ${ }^{72,73}$, with significant consequence for water management, agriculture, forestry and biodiversity. Thus, we argue that it is imperative that the state of the hydroclimate in spring should become an essential topic for further studies. A key element will be to understand the drivers of hydroclimate extremes in spring and why the prevailing large-scale circulation has shifted towards more blocking-like circulation over central Europe. Finally, we conclude that the analysis of co-variability between the large-scale atmospheric circulation and hydroclimate extremes provides a useful detection tool to find plausible physical mechanisms explaining observed changes in the regimes of climate extremes over Europe.

\section{METHODS}

Observational and model data

Meteorological data used in this study comprise: monthly precipitation amounts (PP), monthly mean air temperature (TT), monthly maximum temperature $\left(T_{x}\right)$, and monthly minimum temperature $\left(T_{n}\right)$ obtained from the E-OBS 20.0e version dataset ${ }^{74}$. The E-OBS dataset is based on the European Climate Assessment and Dataset station information (ECA\&D), and consist of daily data from 01.01.1950 until near-present, with a spatial resolution of $0.1 \times 0.1^{\circ}$. As our focus here is on the transitional season, we estimated the meteorological drought for April using both the Standardized Precipitation Index (SPI) $)^{75}$ and the Standardized Precipitation Evapotranspiration Index (SPEI) ${ }^{76}$. A one-month accumulation period was chosen for both cases (i.e., SPI1 and SPEI1). The SPI1 and SPEI1 indices were computed based on the E-OBS data set (PP, $\mathrm{T}_{x}$, and $\mathrm{T}_{n}$ ). For the SPEl1 computation, we have used the Hargreaves equation ${ }^{77}$. The Hargreaves equation estimates daily PET based on each day's mean temperature, the difference between the daily minimum and maximum temperature (as a proxy for net radiation), and an estimate of (extraterrestrial) radiation based on the latitude and day of the year.

The regional precipitation, mean air temperature, and sunshine duration (SD) were extracted from the German Meteorological Service (DWD, ftp:// opendata.dwd.de/climate_environment/CDC/). The monthly time series used in this study covers the period from January 1881 to April 2020 for PP and $\Pi$, and January 1951 to April 2020 for SD. The PP and TT time series are calculated back to 1881 , with quality controlled station data. For stations with missing values, the average of the neighboring stations is used to fill the gaps. The DWD datasets pass through several steps of quality control. For a detailed description of each the quality controlled steps see Kaspar et $\mathrm{al}^{78}$. For the daily weather patterns, we make use of the objective weather types classification of German Meteorological Service. This data set covers the period 1980-2020.

We also analyze the changes in resulting hydrologic variability for a range of variables including streamflow, soil moisture, and evapotranspiration. The monthly streamflow data for the Elbe River at Neu Darchau gauging station was provided by the German Hydrological Institute (www. bfg.de) and covers the period January 1875-April 2020. Long-term hydrologic reconstructions of the monthly soil moisture and evapotranspiration fluxes were taken from a well-established mesoscale Hydrologic Model $(\mathrm{mHM})^{79,80}$. $\mathrm{mHM}$ is a grid-based conceptual model simulating 
dominant hydrological processes on the Earth's surface, in the root-zone soil and subsurface groundwater compartments (see www.ufz.de/mhm for more details). The model parameterizations were rigorously evaluated in the previous studies over Europe with satisfying performance over a set of hydrologic indicators ${ }^{13,81,82}$. A consistently merged meteorological forcing datasets were used to drive the model over the last two-centuries that include the reconstructed climate fields of monthly precipitation and temperature from Casty et al. prior 1900, the CRU dataset ${ }^{83}$ during 1901-1950, and the E-OBS dataset for the period 1951-2020. More details about the model setup can be found in Hanel et $\mathrm{al}^{13}$.

To analyze the large-scale atmospheric circulation we have used the daily and monthly $500 \mathrm{mb}$ geopotential height (Z500) and the monthly meridional and zonal wind at $500 \mathrm{mb}$ which was extracted from the NCEP-NCAR 40-year reanalysis project ${ }^{84}$. This dataset has a spatial resolution of $2.5 \times 2.5^{\circ}$ and covers the period January 1948-present. To extend back in time the analysis of the large-scale atmospheric circulation we have used also the monthly geopotential height, zonal and meridional wind at $500 \mathrm{mb}$ from the 20th Century Reanalysis data V $3^{53}$, covering the period from January 1836 to December 2015 and with a spatial resolution of $2^{\circ} \times 2^{\circ}$.

\section{Canonical Correlation Analysis}

To identify the coupled PP and the Z500 patterns, we employed a Canonical Correlation Analysis (CCA). CCA is a powerful multivariate technique used to identify pairs of patterns with the maximum correlation between their associated time series ${ }^{85}$. We used CCA to identify coupled pairs of modes and their associated time components in the PP/Z500 data sets. Before the CCA, the dimensionality of the PP and Z500 fields was reduced by an EOF analysis. The first 10 EOFs of PP and Z500 were retained as input in the CCA, The first 10 EOFs of April PP capture $~ 90 \%$ of the total variance, while the first 10 EOFs of April Z500 capture $\sim 92 \%$ of the total variance. The optimal number of retained EOFs was chosen as a way that by adding or removing one EOF, the results of CCA would not change significantly ${ }^{85}$.

\section{D Atmospheric blocking index}

The two-dimensional (2D) atmospheric blocking index, used in this study, is based on the definition from Scherrer et al. $(2006)^{48}$. To compute the 2D blocking index, we have used the daily geopotential height at $500 \mathrm{mb}$ extracted from the NCEP-NCAR 40-year reanalysis project ${ }^{84}$. The 2D blocking index is an extension of the one-dimensional (1D) Tibaldi-Molteni (TM) inde ${ }^{86}$ to a two-dimensional map of blocking frequencies at every grid point. The southern geopotential height gradient (GHGS) and the northern geopotential height gradient (GHGN) for each grid point are evaluated as follows:

$$
\begin{aligned}
& \text { GHGS }=\left(Z\left(\phi_{0}\right)-Z\left(\phi_{0}-15^{0}\right)\right) / 15^{0} \\
& \text { GHGN }=\left(Z\left(\phi_{0}+15^{0}\right)-Z\left(\phi_{0}\right)\right) / 15^{0}
\end{aligned}
$$

where $\phi_{0}$ is the latitude of the considered grid point varying from $35^{\circ} \mathrm{N}$ to $75^{\circ}$.

For each month we have calculated the ratio between the number of days when a certain grid point was blocked, i.e., the conditions GHGS $>0$ and $\mathrm{GHGN}<\left(-10 \mathrm{~m} /{ }^{\circ}\right.$.lat $)$ are simultaneously satisfied for at least five consecutive days.

\section{Composite analysis}

To identify the physical mechanism responsible for the connection between the April $A A$ and the $2 D$ atmospheric blocking frequency (Fig. $6 \mathrm{~b}$ ), we constructed the composite maps between the time series of April for the years of when the AA was higher than +0.75 standard deviation (High), respectively lower than -1 standard deviation (Low). This threshold was chosen as a compromise between the strength of the climate anomalies associated to flow anomalies and the number of maps which satisfy these criteria. Further analysis has shown that the results are not sensitive to the exact threshold value used for our composite analysis. In the paper we will show just the maps corresponding to the difference (DIFF) between High-Low years.

\section{DATA AVAILABILITY}

All datasets used as input in our study can be found in the respective references.

\section{CODE AVAILABILITY}

All code necessary to perform the reported analyses can be obtained from the corresponding author.

Received: 12 June 2020; Accepted: 4 November 2020; Published online: 07 December 2020

\section{REFERENCES}

1. Godfray, H. C. J. et al. Food security: The challenge of feeding 9 billion people. Science 327, 812-818 (2010).

2. Schmidhuber, J. \& Tubiello, F. N. Global food security under climate change. Proc. Natl Acad. Sci. USA 104, 19703-19708 (2007).

3. Clark, J. S. et al. The impacts of increasing drought on forest dynamics, structure, and biodiversity in the United States. Glob. Change Biol. 22, 2329-2352 (2016).

4. D'Orangeville, L. et al. Drought timing and local climate determine the sensitivity of eastern temperate forests to drought. Glob. Chang. Biol. 24, 2339-2351 (2018).

5. Arnell, N. W. The effect of climate change on hydrological regimes in Europe: A continental perspective. Glob. Environ. Change 9, 5-23 (1999).

6. Myhre, G. et al. in Climate Change 2013: The Physical Science Basis. Contribution of Working Group I to the Fifth Assessment Report of the Intergovernmental Panel on Climate Change (eds Stocker, T. F. et al.) (Cambridge Univ. Press, 2013).

7. Williams, A. P. et al. Contribution of anthropogenic warming to California drought during 2012-2014. Geophys. Res. Lett. 42, 6819-6828 (2015).

8. Yoon, J. H. et al. Increasing water cycle extremes in California and in relation to ENSO cycle under global warming. Nat. Commun. 6, 8657 (2015).

9. Bakke, S. J., lonita, M. \& Tallaksen, L. M. The 2018 northern European hydrological drought and its drivers in a historical perspective. Hydrol. Earth Syst. Sci. Discuss. 2020, 1-44 (2020).

10. Barriopedro, D., Fiscer, E. M., Luterbacher, J., Trigo, R. M. \& García-Herrera, R. The Hot Summer of 2010: Map of Europe. Science 332, 220-224 (2011).

11. Ionita, M. et al. The European 2015 drought from a climatological perspective. Hydrol. Earth Syst. Sci. 21, 1397-1419 (2017).

12. Hari, V., Rakovec, O., Markonis, Y., Hanel, M. \& Kumar, R. Increased future occurrences of the exceptional 2018-2019 Central European drought under global warming. Sci. Rep. 10, 12207 (2020).

13. Hanel, M. et al. Revisiting the recent European droughts from a long-term perspective. Sci. Rep. 8, 9499 (2018).

14. Ionita, M. \& Nagavciuc, V. Forecasting low flow conditions months in advance through teleconnection patterns, with a special focus on summer 2018. Sci. Rep. 10, 13258 (2020).

15. Munich R. E. Heatwaves, Drought and Forest Fires in Europe: Billions of Dollars in Losses for Agricultural Sector (Munich R. E., 2020).

16. Hurrell, J. W. Decadal trends in the North Atlantic oscillation: Regional temperatures and precipitation. Science 269, 676-679 (1995).

17. Lavers, D. A. \& Villarini, G. Atmospheric rivers and flooding over the central United States. J. Clim. 26, 7829-7836 (2013).

18. Bladé, I., Liebmann, B., Fortuny, D. \& van Oldenborgh, G. J. Observed and simulated impacts of the summer NAO in Europe: Implications for projected drying in the Mediterranean region. Clim. Dyn. 39, 709-727 (2012).

19. Bueh, C. \& Nakamura, H. Scandinavian pattern and its climatic impact. Q. J. $R$. Meteorol. Soc. 133, 2117-2132 (2007).

20. García-Herrera, R. \& Barriopedro, D. Climate of the Mediterranean and North Africa. Clim. Sci. https://doi.org/10.1093/acrefore/9780190228620.013.509 (2017).

21. Ionita, M. The Impact of the East Atlantic/Western Russia Pattern on the Hydroclimatology of Europe from Mid-Winter to Late Spring. Climate 2, 296-309 (2014).

22. Van Oldenborgh, G. J., Burgers, G. \& Tank, A. K. On the El Nino teleconnection to spring precipitation in Europe. Int. J. Climatol. 20, 565-574 (2000).

23. Rimbu, N., Dima, M., Lohmann, G. \& Musat, I. Seasonal prediction of Danube flow variability based on stable teleconnection with sea surface temperature. Geophys. Res. Lett. 32, L21704 (2005).

24. Mariotti, A., Zeng, N. \& Lau, K. M. Euro-Mediterranean rainfall and ENSO-a seasonally varying relationship. Geophys. Res. Lett. 29, 591-594 (2002).

25. Vicente-Serrano, S. M. \& López-Moreno, J. I. Nonstationary influence of the North Atlantic Oscillation on European precipitation. J. Geophys. Res. Atmos. 113, 1-14 (2008).

26. Huth, R. et al. Classifications of atmospheric circulation patterns: Recent advances and applications. Ann. N.Y. Acad. Sci. 1146, 105-152 (2008).

27. Fleig, A. K., Tallaksen, L. M., Hisdal, H. \& Hannah, D. M. Regional hydrological drought in north-western Europe: Linking a new Regional Drought Area Index with weather types. Hydrol. Process. 25, 1163-1179 (2011). 
28. Ramos, A. M., Cortesi, N. \& Trigo, R. M. Circulation weather types and spatial variability of daily precipitation in the Iberian Peninsula. Front. Earth Sci. 2, 1-17 (2014).

29. Trigo, R. M., Trigo, I. F., DaCamara, C. C. \& Osborn, T. J. Climate impact of the European winter blocking episodes from the NCEP/NCAR reanalyses. Clim. Dyn. 23, 17-28 (2004).

30. Lee, M. Y., Hong, C. C. \& Hsu, H. H. Compounding effects of warm sea surface temperature and reduced sea ice on the extreme circulation over the extratropical North Pacific and North America during the 2013-2014 boreal winter. Geophys. Res. Lett. 42, 1612-1618 (2015).

31. Pfahl, S. \& Wernli, H. Quantifying the relevance of atmospheric blocking for colocated temperature extremes in the Northern Hemisphere on (sub-)daily time scales. Geophys. Res. Lett. 39, L12807 (2012).

32. Rimbu, N., Stefan, S. \& Necula, C. The variability of winter high temperature extremes in Romania and its relationship with large-scale atmospheric circulation. Theor. Appl. Climatol. 121, 121-130 (2014).

33. Houze, R. A., Rasmussen, K. L., Medina, S., Brodzik, S. R. \& Romatschke, U. Anomalous atmospheric events leading to the summer 2010 floods in Pakistan. Bull. Am. Meteorol. Soc. 92, 291-298 (2011).

34. Sousa, P. M. et al. Responses of European precipitation distributions and regimes to different blocking locations. Clim. Dyn. 48, 1141-1160 (2017).

35. Lenggenhager, S. \& Martius, O. Atmospheric blocks modulate the odds of heavy precipitation events in Europe. Clim. Dyn. 53, 4155-4171 (2019).

36. Holton, J. R. \& Hakim, G. J. An Introduction to Dynamic Meteorology Vol. 88 (Elsevier Academic Press, 2013).

37. Coumou, D. \& Rahmstorf, S. A decade of weather extremes. Nat. Clim. Chang. 2 , 491-496 (2012)

38. Hänsel, S., Ustrnul, Z., Łupikasza, E. \& Skalak, P. Assessing seasonal drought variations and trends over Central Europe. Adv. Water Resour. 127, 53-75 (2019).

39. Hirschi, M. et al. Observational evidence for soil-moisture impact on hot extremes in southeastern Europe. Nat. Geosci. 4, 17-21 (2011).

40. Mueller, B. \& Seneviratne, S. I. Hot days induced by precipitation deficits at the global scale. Proc. Natl Acad. Sci. USA 109, 12398-12403 (2012).

41. Quesada, B., Vautard, R., Yiou, P., Hirschi, M. \& Seneviratne, S. I. Asymmetric European summer heat predictability from wet and dry southern winters and springs. Nat. Clim. Change 2, 736-741 (2012).

42. Swain, D. L., Horton, D. E., Singh, D. \& Diffenbaugh, N. S. Trends in atmospheric patterns conducive to seasonal precipitation and temperature extremes in California. Sci. Adv. 2, 1-14 (2016).

43. Al, K. E. T., Kingston, D. G., Stagge, J. H., Tallaksen, L. M. \& Hannah, D. M. EuropeanScale Drought: Understanding Connections between Atmospheric Circulation and Meteorological Drought Indices. J. Clim. 28, 505-516 (2015).

44. Ionita, M., Lohmann, G., Rimbu, N., Chelcea, S. \& Dima, M. Interannual to decadal summer drought variability over Europe and its relationship to global sea surface temperature. Clim. Dyn. 38, 363-377 (2012).

45. Ionita, M., Boroneant, C. \& Chelcea, S. Seasonal modes of dryness and wetness variability over Europe and their connections with large scale atmospheric circulation and global sea surface temperature. Clim. Dyn. 45, 2803-2829 (2015).

46. Horton, D. E. et al. Contribution of changes in atmospheric circulation patterns to extreme temperature trends. Nature 522, 465-469 (2015).

47. Barriopedro, D., García-Herrera, R. \& Trigo, R. M. Application of blocking diagnosis methods to General Circulation Models. Part I: A novel detection scheme. Clim Dyn. 35, 1373-1391 (2010).

48. Scherrer, S. C., Croci-Maspoli, M., Schwierz, C. \& Appenzeller, C. Two-dimensional indices of atmospheric blocking and their statistical relationship with winter climate patterns in the Euro-Atlantic region. Int. J. Climatol. 26, 233-249 (2006).

49. Bissolli, P. \& Dittmann, E. The objective weather type classification of the German weather service and its possibilities of application to environmental and meteorological investigations. Meteorol. Z. 10, 253-260 (2001).

50. Ionita, M. Interannual summer streamflow variability over Romania and its connection to large-scale atmospheric circulation. Int. J. Climatol. 35, 4186-4196 (2015)

51. Schubert, S. D., Wang, H., Koster, R. D., Suarez, M. J. \& Groisman, P. Y. Northern Eurasian heat waves and droughts. J. Clim. 27, 3169-3207 (2014).

52. Della-Marta, P. M. et al. Summer heat waves over western Europe 1880-2003, their relationship to large-scale forcings and predictability. Clim. Dyn. 29, 251-275 (2007).

53. Slivinski, L. C. et al. Towards a more reliable historical reanalysis: Improvements for version 3 of the Twentieth Century Reanalysis system. Q. J. R. Meteorol. Soc. 145, 2876-2908 (2019).

54. Walter, K. \& Graf, H. F. On the changing nature of the regional connection between the North Atlantic Oscillation and sea surface temperature. J. Geophys. Res. Atmos. 107, 4338 (2002).

55. Ionita, M., Lohmann, G. \& Rimbu, N. Prediction of spring Elbe discharge Based on stable teleconnections with winter global temperature and precipitation. J. Clim. 21, 6215-6226 (2008)
56. Predicting the June 2013 European Flooding based on Precipitation. Soil Moisture and Sea Level Pressure. J. Hydrometeorol. 16, 598-614 (2014).

57. Nagavciuc, V. et al. Different climate response of three tree ring proxies of Pinus sylvestris from the Eastern Carpathians, Romania. Dendrochronologia 54, 56-63 (2019).

58. Nagavciuc, V. et al. Climate signals in carbon and oxygen isotope ratios of Pinus cembra tree-ring cellulose from Călimani Mountains, Romania. Int. J. Climatol. 40, 2539-2556 (2020).

59. Ionita, M. Mid Range Forecasting of the German Waterways Streamflow Based on Hydrologic, Atmospheric and Oceanic data. Beri. Polar Meeresforsc. https://doi.org/ 10.2312/BzPM_0711_2017 (2017).

60. Stott, P. A., Stone, D. A. \& Allen, M. R. Human contribution to the European heatwave of 2003. Nature 432, 610-614 (2004).

61. Meehl, GeraldA. \& Tebaldi, Claudia More Intense, More Frequent, and Longer Lasting Heat Waves in the 21st Century. Science 305, 994-997 (2004).

62. Francis, J. A. The Arctic matters: extreme weather responds to diminished Arctic Sea ice. Environ. Res. Lett. 10, 091002 (2015).

63. Cohen, J. et al. Recent Arctic amplification and extreme mid-latitude weather Nat. Geosci. 7, 627-637 (2014).

64. Cohen, J. et al. Divergent consensuses on Arctic amplification influence on midlatitude severe winter weather. Nat. Clim. Change 10, 20-29 (2020).

65. Zhang, R., Sun, C., Zhu, J., Zhang, R. \& Li, W. Increased European heat waves in recent decades in response to shrinking Arctic sea ice and Eurasian snow cover. npj Clim. Atmos. Sci. 3, 7 (2020).

66. Taylor, K. E., Stouffer, R. J. \& Meehl, G. A. An Overview of CMIP5 and the Experiment Design. Bull. Am. Meteorol. Soc. 93, 485-498 (2012). https://www.bafg.de/DE/ 05_Wissen/04_Pub/04_Buecher/niedrigwasser_2018_dokument_EN.pdf;jsessionid= 4978C7561D9D94D7778B59489923360D.live11291?_blob=publicationFile.

67. Routson, C. C. et al. Mid-latitude net precipitation decreased with Arctic warming during the Holocene. Nature 568, 83-87 (2019).

68. Shepherd, T. G. Atmospheric circulation as a source of uncertainty in climate change projections. Nat. Geosci. 7, 703-708 (2014).

69. BFG. Low-Flow in 2018. https://doi.org/10.5675/BfG-Niedrigwasserbroschuere (2018).

70. Swain, D. L. et al. Remote Linkages to Anomalous Winter Atmospheric Ridging Over the Northeastern Pacific. J. Geophys. Res. Atmos. 122, 12.194-12.209 (2017).

71. Samaniego, L. et al. Anthropogenic warming exacerbates European soil moisture droughts. Nat. Clim. Change 8, 421-426 (2018).

72. Dai, A. Increasing drought under global warming in observations and models. Nat. Clim. Change 3, 52-58 (2013).

73. Dubrovsky, M., Trnka, M., Holman, I. P., Svobodova, E. \& Harrison, P. A. Developing a reduced-form ensemble of climate change scenarios for Europe and its application to selected impact indicators. Clim. Change 128, 169-186 (2014).

74. Cornes, R. C., Van Der Schrier, G., Van Den Besselaar, E. J. M. \& Jones, P. D. An Ensemble Version of the E-OBS Temperature and Precipitation Datasets. Geophys. Res. At. 123, 9391-9409 (2018).

75. McKee, T. B., Nolan, J. \& Kleist, J. The relationship of drought frequency and duration to time scales. in Proc. Eighth Conference on Applied Climatology 1-6 (Anaheim, California, 1993).

76. Vicente-Serrano, S. M., Beguería, S. \& López-Moreno, J. I. A multiscalar drought index sensitive to global warming: The standardized precipitation evapotranspiration index. J. Clim. 23, 1696-1718 (2010).

77. Hargreaves, G. H. \& Samani, Z. A. Reference Crop Evapotranspiration from Temperature. Appl. Eng. Agric 1, 96-99 (1985).

78. Kaspar, F. et al. Monitoring of climate change in Germany-data, products and services of Germany's National Climate Data Centre. Adv. Sci. Res. 10, 99-106 (2013).

79. Kumar, R., Samaniego, L. \& Attinger, S. Implications of distributed hydrologic model parameterization on water fluxes at multiple scales and locations. Water Resour. Res. 49, 360-379 (2013).

80. Samaniego, L., Kumar, R. \& Attinger, S. Multiscale parameter regionalization of a grid-based hydrologic model at the mesoscale. Water Resour. Res. 46, WO5523 (2010).

81. Rakovec, O. et al. Multiscale and multivariate evaluation of water fluxes and states over european river Basins. J. Hydrometeorol. 17, 287-307 (2016).

82. Samaniego, L. et al. Hydrological forecasts and projections for improved decisionmaking in the water sector in europe. Bull. Am. Meteorol. Soc. 100, 2451-2471 (2019).

83. Harris, I., Jones, P. D., Osborn, T. J. \& Lister, D. H. Updated high-resolution grids of monthly climatic observations-the CRU TS3.10 Dataset. Int. J. Climatol. 34 623-642 (2014).

84. Kalnay, E. et al. NCAR 40-year reanalysis project. Bull. Am. Meteorol. Soc. 77, 437-470 (1996).

85. von Storch, H. \& Zwiers, F. W. Statistical Analysis in Climate Research. Statistical Analysis in Climate Research (Cambridge University Press, 1999). 
86. Tibaldi, S. \& Molteni, F. On the operational predictability of blocking. Tellus $\mathbf{4 2 ,}$ 343-365 (1990).

87. Lenssen, N. J. L. et al. Improvements in the GISTEMP Uncertainty Model. J. Geophys. Res. Atmos. 124, 6307-6326 (2019).

\section{ACKNOWLEDGEMENTS}

This study was promoted by Helmholtz funding through the Polar Regions and Coasts in the Changing Earth System (PACES) program of the AWl. Funding by the AWI Strategy Fund Project - PalEX and by the Helmholtz Climate Initiative - REKLIM is gratefully acknowledged. Contribution of RK and OR was supported by the bilateral project XEROS (eXtreme EuRopean drOughtS: multimodel synthesis of past, present and future events), funded by the Deutsche Forschungsgemeinschaft (grant RA 3235/ 1-1) and Czech Science Foundation (grant 19-24089J).

\section{AUTHOR CONTRIBUTIONS}

M.I. designed the study and wrote the paper. V.N., R.K. and O.R. helped with the writing of the paper and interpreting the results.

\section{FUNDING}

Open Access funding enabled and organized by Projekt DEAL.

\section{COMPETING INTERESTS}

The authors declare no competing interests.

\section{ADDITIONAL INFORMATION}

Supplementary information is available for this paper at https://doi.org/10.1038/ s41612-020-00153-8.

Correspondence and requests for materials should be addressed to M.I.

Reprints and permission information is available at http://www.nature.com/ reprints

Publisher's note Springer Nature remains neutral with regard to jurisdictional claims in published maps and institutional affiliations.

Open Access This article is licensed under a Creative Commons Attribution 4.0 International License, which permits use, sharing, adaptation, distribution and reproduction in any medium or format, as long as you give appropriate credit to the original author(s) and the source, provide a link to the Creative Commons license, and indicate if changes were made. The images or other third party material in this article are included in the article's Creative Commons license, unless indicated otherwise in a credit line to the material. If material is not included in the article's Creative Commons license and your intended use is not permitted by statutory regulation or exceeds the permitted use, you will need to obtain permission directly from the copyright holder. To view a copy of this license, visit http://creativecommons. org/licenses/by/4.0/.

(c) The Author(s) 2020 